\title{
Experimental Study of Influencing Factors and Kinetics in Catalytic Removal of Methylene Blue with $\mathrm{TiO}_{2}$ Nanopowder
}

\author{
Marziyeh Salehi $^{1,2}$, Hassan Hashemipour ${ }^{1,3, *}$, Mohammad Mirzaee ${ }^{2}$ \\ ${ }^{1}$ Chemical Engineering Department, Shahid Bahonar University, Kerman, 7616914111, Iran \\ ${ }^{2}$ Environmental Sciences Department, International Center for Science, High Technology \& Environmental \\ Science, Kerman, 7631133131, Iran \\ ${ }^{3}$ Mineral Industries Research Institute, Shahid Bahonar University, Kerman, 7616914111, Iran
}

\begin{abstract}
In this research, degradation of methylene blue as a dye pollutant was investigated in the presence of $\mathrm{TiO}_{2}$ nanopowders using photolysis and sonolysis systems separately and simultaneously. Effect of different parameters such as catalyst dosage, initial concentration of dye, UV power, $\mathrm{pH}$ and type of catalyst on the removal efficiency was ascertained. The results showed that basic $\mathrm{pH}$ is proper for the photocatalytic removal of the dye. Furthermore higher UV power and lower initial concentration of dye leads to higher removal percent. Moreover $\mathrm{TiO}_{2}$ showed more photocatalytic activity than $\mathrm{ZnO}$ in the nanopowder form. The experimental kinetic data followed the pseudo-first order model in both photocatlytic and sonophotocatalytic processes but the rate constant of sonophotocatalysis is higher than it at photocatalysis process. Finally the reaction order of the rate law respect to nanocatalyst dosage in photocatalysis process is obtained 1.45. High activation energy of this process shows its high sensitivity to temperature.
\end{abstract}

Keywords Methylene Blue, $\mathrm{TiO}_{2}$ Nanopowder, Photocatalysis, Sonophotolysis, Kinetic Study

\section{Introduction}

Dyestuffs are the materials which extensively used in the textile and other printing industries. The color and toxicity which dyes impart to water bodies are very undesirable and harmful to the water users for aesthetic and environmental reasons $[1,2]$. From an environmental point of view, as some synthetic dyes have toxic and carcinogenic properties, they are of great concern. Approximately about $1-20 \%$ of the overall dye production of the world is discharged from various industries such as dyestuff manufacturing, dyeing, printing, and textile finishing $[3,4]$. Methylene blue (MB) is a cationic dye, used extensively for dying cotton, wool and silk. The risk of the existence of this dye in waste water may be arisen from the burns effect of eye, nausea, vomiting and diarrhea[4,5]. MB has a maximum absorption in the $660 \mathrm{~nm}$ visible area[6].

In general, several methods have been developed for the removal of dyes from effluents including (1) physical methods employing precipitation, adsorption, and reverse osmosis; (2) chemical methods via oxidation (using air oxygen; ozone, $\mathrm{NaOC} 1$, and $\mathrm{H}_{2} \mathrm{O}_{2}$ as oxidants) and reduction

* Corresponding author:

h-hashemipour@uk.ac.ir (Hassan Hashemipour)

Published online at http://journal.sapub.org/ajee

Copyright (C) 2012 Scientific \& Academic Publishing. All Rights Reserved (e.g., $\mathrm{Na}_{2} \mathrm{~S}_{2} \mathrm{O}_{4}$ ); and (3) biological methods including aerobic and anaerobic treatment. The disadvantages of these conventional methods are sludge formation, waste disposal and high operation cost, time consuming and ineffectiveness in cases where complicated aromatic compounds are presented $[7,8]$.

Advanced oxidation processes (AOPs) have been defined broadly on the intermediacy of the hydroxyl radicals $\left(\mathrm{OH}^{\bullet}\right)$ in driving the oxidation processes. Since AOPs provide different routes to $\mathrm{OH}^{\bullet}$ radical production, easier tailoring of the treatment process occurs. Ozone, hydrogen peroxide, ultrasonic, ultraviolet radiation, etc are some methods of AOPs that can be used individually or in different combination forms to generate the hydroxyl radicals $[9,10]$.

It is evident that the conduction band electrons $\left(e^{-}\right)$and the valence band holes $\left(h^{+}\right)$are formed when the aqueous suspension of $\mathrm{TiO}_{2}$ irradiates with photon energy higher than the band gap (figure 1).

The process of photodegradation starts when $\mathrm{TiO}_{2}$ absorbs a UV radiation of energy equal or higher than its band gap (3.2 eV for anatase; $3.0 \mathrm{eV}$ for rutile). This leads to the formation of free electrons in the conduction band and holes in the semiconductor valence band. The energized electrons can either recombine with the holes (and then dissipate the absorbed energy as heat) or the electron-hole pairs can participate in redox reactions. They can react with electron acceptors/donors adsorbed on the surface of the photocata- 
lyst. Alternatively, the solid side at the semiconductor/liquid junction creates an electrical field that separates the electrons-holes pairs that fail to recombine. The electron field allows the holes to migrate to the illuminated part of the $\mathrm{TiO}_{2}$ and the electrons to migrate to the unlit region of the $\mathrm{TiO}_{2}$ particle surface. Essentially, it is accepted that the initial steps of photocatalytic degradation of a species is the reaction with extremely reactive but short-lived hydroxyl radicals $\left(\mathrm{OH}^{\bullet}\right)$ or direct hole trapping. The $\mathrm{OH}^{\bullet}$ is formed either in the highly hydroxylated semiconductor surface or by direct oxidation of the pollutant molecules under UV radiation. There is also a possibility that both methods of forming $\mathrm{OH}^{\bullet}$ occurs in these situation simultaneously. The reduction of adsorbed oxygen species occurs immediately after this process. Dissolved oxygen molecules (in the aqueous system), or other electron acceptors available in the aqueous system can cause this reduction[11,12].

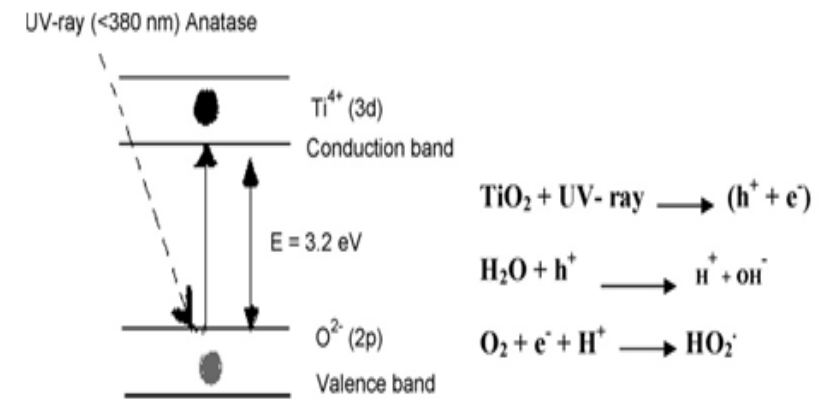

Figure 1. Energy band gap created on $\mathrm{TiO}_{2}$ surface

After successive free radical attack and fragmentation, most organics are mineralized to water, carbon dioxide and mineral acids[2,13]. González investigated the sonophotocatalytic degradation of methylene blue and found that degradation reaction followed apparent first-order kinetics and was dependent on the $\mathrm{pH}$ solution with the highest degradation at $\mathrm{pH} 7[14]$.

There is a need to determine the optimal conditions of experimental parameters for effective application of dye wastewater treatment by AOP processes. In this study, a cationic dye basic blue 9 is selected and examined the various parameters in photocatalysis and sonocatalysis treatment using nanopowder $\mathrm{TiO}_{2}$ in a batch process and then the optimum conditions for removal of color and aromatic part of the dye are reported. Moreover comparison of the two semiconductor photocatalyst, $\mathrm{TiO}_{2}$ and $\mathrm{ZnO}$, is done at the same conditions. Finally kinetic study of the reactions is considered and kinetic parameters are determined in detail.

\section{Experimental}

\subsection{Materials}

Titanium dioxide (Degussa P25) nanopowder was utilized as a degradation catalyst. It is mostly in the anatase form with a surface area of $50 \mathrm{~m}^{2} / \mathrm{g}$ corresponding to a mean particle size of $20 \mathrm{~nm}$ and purity $>99 \%$. Zinc oxide nanopowder as another catalyst of the reaction was used with average particle size of $25 \mathrm{~nm}$, specific surface area 44 $\mathrm{m}^{2} / \mathrm{g}$ and purity $99.7 \%$ that was prepared from Nano Nader-Sama Company.

In this paper, methylene blue was obtained from Merck in the laboratory grade and used without further purification. Adjustment of $\mathrm{pH}$ of the dye solutions prior to degradation was carried out with $\mathrm{NaOH}$ or $\mathrm{H}_{2} \mathrm{SO}_{4}$ from Merck. Distilled water was used in all experiments.

\subsection{Apparatus}

The sonolysis experiments were carried out in an ultrasonic bath with controlling power and temperature. Four UV-A (365 nm) 6W Hitachi black light lamps were applied to irradiate in the photocatalytic experiments. The UV lamps were installed on the top of the ultrasonic bath for alternative photo and/or sono irradiation cases. The reaction region was covered with aluminum foil to create light reflection and to prevent light emission to surroundings. The dye concentration was analyzed with a VinCary 50 UV-vis Spectrophotometer. The solution's $\mathrm{pH}$ was detected with a $\mathrm{pH}$ meter (Metrohm).

\subsection{Methods and Analyses}

A solution containing proper concentration of the dye and dosage of $\mathrm{TiO}_{2}$ nanopowder was prepared and imposed to ultraviolet or ultrasonic depending on the photocatalytic or sonocatalytic cases over a pre-determined period of time. Before analysis, the aqueous samples were filtered through $0.22 \mu \mathrm{m}$ Biofil syringe filter to remove $\mathrm{TiO}_{2}$ nanopowders. The absorbance measurements with UV-visible spectrophotometer at $660 \mathrm{~nm}$ (which is maximum absorption wavelength of $\mathrm{MB}$ ) were employed to calculate the dye concentration from the calibration curve (absorbance vs. MB concentration). The removal percent of MB was calculated by using the equation given below:

$$
\eta=\left(\mathrm{C}_{0}-\mathrm{C}_{\mathrm{t}}\right) / \mathrm{C}_{0}=\left(\mathrm{A}_{0}-\mathrm{A}_{\mathrm{t}}\right) / \mathrm{A}_{0}
$$

Where $\mathrm{C}_{0}$ and $\mathrm{C}_{t}$ are dye concentration at initial and any time respectively. The parameters $\mathrm{A}_{0}$ and $\mathrm{A}_{\mathrm{t}}$ are the absorbance of the MB solutions in the $660 \mathrm{~nm}$ wavelength at initial and any time respectively.

\section{Results and Discussion}

\subsection{Effect of Catalyst Dosage}

The effect of the amount of $\mathrm{TiO}_{2}$ dosage on the MB removal was studied and the results are shown in figure 2 for sonocatalysis (US), photocatalysis (UV) and sonophotocatalysis (US/UV) processes. The experiments were carried out with a $10 \mathrm{ppm}$ dye solution for $60 \mathrm{~min}$.

Basically, the removal efficiency increases with increasing the catalysis dosage and then stays nearly constant in a specific catalyst dosage. The most effective decomposition of $\mathrm{MB}$ was observed at $0.2 \mathrm{~g} / \mathrm{l}$ of $\mathrm{TiO}_{2}$ for photo and sonophotocatalysis and $1 \mathrm{~g} / \mathrm{l}$ for sonocatalysis reactions. The 
reason of this observation is thought to be the fact that when all dye molecules are adsorbed on $\mathrm{TiO}_{2}$, the addition of higher quantities of $\mathrm{TiO}_{2}$ would have no effect on the degradation efficiency. Another cause for this is supposedly an increased opacity of the suspension, brought about as a result of excess of $\mathrm{TiO}_{2}$ particles $[15,16]$.

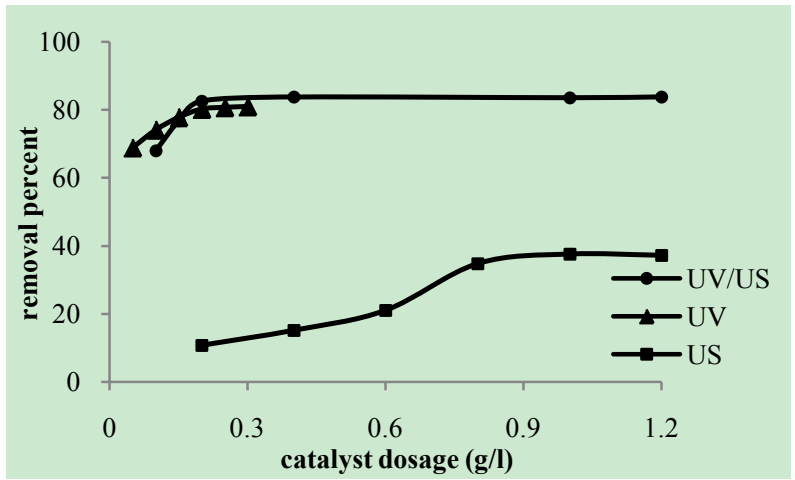

Figure 2. Effect of dosage of $\mathrm{TiO}_{2}$ on $\mathrm{MB}$ removal

In addition the removal percentage of $\mathrm{MB}$ in sonocatalytic process increases with an increasing in catalyst dosage and then reaches to the constant amount of $1 \mathrm{~g} / \mathrm{l}$.This is due to the fact that ultrasonic irradiation can also be used as an alternative energy source for $\mathrm{TiO}_{2}$ to generate positive holes without the presence of a UV source[17]. Nanoparticles show a great tendency to aggregate due to high surface energy combined with their high surface area to volume ratio [18] but ultrasonic irradiation can disperse the catalyst particles more efficiently. Despite all these things, when the amount of $\mathrm{TiO}_{2}$ increases more than $1 \mathrm{~g} / 1$ the catalyst particles may agglomerate and this results decreasing in removal percentage[19]. As the results show, the optimum amount of catalyst for sonocatalysis is more than the amount for photocatalysis. As can be seen from this figure, the optimum amount of photocatalyst in simultaneous photocatalysis and sonocatalysis is the same as the amount in photocatalysis $(0.2 \mathrm{~g} / \mathrm{l})$. In sonophotocatalysis both sonolysis and photocatalysis make roles but photocatalysis is the rate limiting ones.

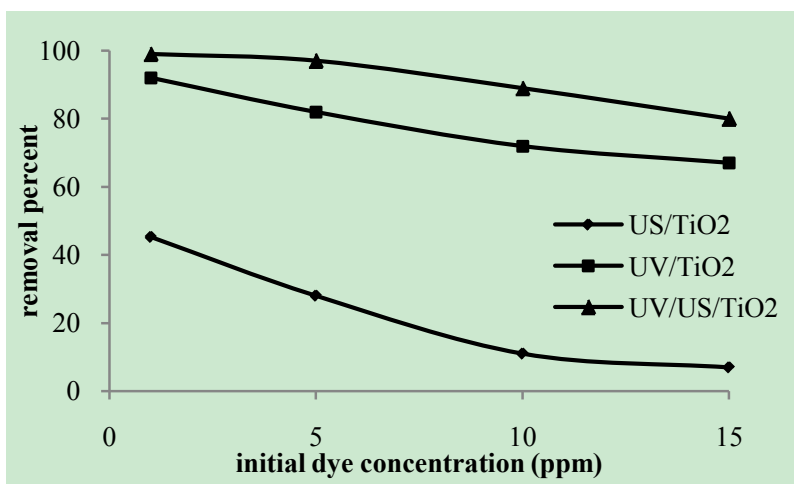

Figure 3. Effect of initial dye concentration on MB removal

\subsection{Effect of Initial Dye Concentration}

The effect of initial concentration of dye solutions on the removal percentage was investigated at the optimum catalyst dosage determined before $(0.2 \mathrm{~g} / 1$ for photocatalysis and 1 $\mathrm{g} / \mathrm{l}$ for sonocatalysis) for $90 \mathrm{~min}$ during separate and simultaneous photocatalysis and sonocatalysis as were shown in figure 3.

As expected there is a tradeoff between both photo and sonocatalysis degradation conversion of $\mathrm{MB}$ and initial concentration of MB. The reason is that when the initial concentration of dye is increased, more and more dye molecules are adsorbed on the surface of $\mathrm{TiO}_{2}$.

Since the existence of the large amounts of adsorbed dye results the lack of any direct contact with the holes or hydroxyl radicals, this might have an inhibitive effect on the dye degradation. Other possible reasons for these results is the effect of UV screening of the own dye. In high dye concentrations a major amount of UV tends to be absorbed by dye molecules. This reduces the efficiency of the catalytic reaction due to the decline in $\mathrm{OH}^{\circ}$ and $\mathrm{OH}_{2}{ }^{\circ}$ concentrations. Another possible reason is the formation of the by-products during the degradation of mother dye molecules. Moreover the percentage removal decreases rapidly at low $\mathrm{MB}$ concentrations and then changes slowly as the initial concentration increases[20-22].

As seen, more dye removing is observed in photocatalysis than sonocatalysis in all experiments. It indicates that photocatalytic process has higher efficiency than sonocatalysis. The combined processes of photocatalysis and sonolysis produced synergistic effects and showed the highest efficiency in the all initial concentration of dye.

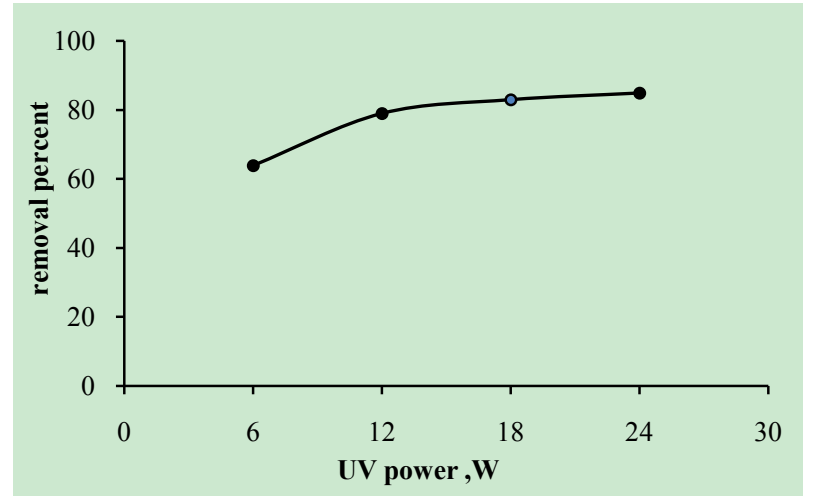

Figure 4. Effect of UV power in the photocatalytic degradation of MB. $\left(0.2 \mathrm{~g} / \mathrm{l} \mathrm{TiO}_{2},[\mathrm{MB}]=10 \mathrm{ppm}\right)$

\subsection{Effect of UV Power}

The effect of UV power on the removal of MB was shown in figure 4. The results show that the removal percent increases with increasing the power of radiation. The increasing in UV power from $6 \mathrm{~W}$ to $12 \mathrm{~W}$ increases the percentage removal from $64 \%$ to $79 \%$ and increasing the UV power from $12 \mathrm{~W}$ to $24 \mathrm{~W}$ the percentage removal from $79 \%$ to $85 \%$ for a $10 \mathrm{ppm}$ solution of dye increases after $60 \mathrm{~min}$ at ambient temperature. The results show that the UV light intensity plays an important role in degradation of $\mathrm{MB}$. Moreover at the range of UV power that the experiments were done, the percentage removal increases rapidly at low power of UV and then changes slowly as the UV power increases. Increasing the power of UV radiation provides more energy to excite the electron of $\mathrm{TiO}_{2}$ and creates more 
electron-hole pairs, thus improve the photocatalytic process $[23,24]$.

\subsection{Effect of PH}

Since $\mathrm{pH}$ of dye solution is a main parameter on the degradation progress, comparative experiments were performed at different $\mathrm{pH}$ values: one acidic $\mathrm{pH}$ (3.3), two basic $\mathrm{pHs}(11.4,13.3)$ and one natural $\mathrm{pH}(7.7)$. The $\mathrm{pH}$ parameter improves the removal percentage and the results are shown in figure 5. The $\mathrm{pH}$ influences the characteristics of the photocatalyst surface charge, so $\mathrm{pH}$ of the solution is a significant parameter in performing the reaction on the surface of semiconductor particles. Point of zero charge (PZC) for $\mathrm{TiO}_{2}$ particles is $\mathrm{pH} \mathrm{PZC}=6.8[3,25]$. The surface of $\mathrm{TiO}_{2}$ has a negative charge in basic media $(\mathrm{pH}>6.8)$, so there is an electrostatic absorption between negative charge surfaces of $\mathrm{TiO}_{2}$ and cationic dyes. As the $\mathrm{pH}$ of the system decreases, the number of surfaces with positive charge increases. The surface sites on $\mathrm{TiO}_{2}$ do not tend to absorb the cations of dyes made by electrostatic propulsion. $\mathrm{H}_{2} \mathrm{SO}_{4}$ and $\mathrm{NaOH}$ were used to $\mathrm{pH}$ adjustment of dye solutions

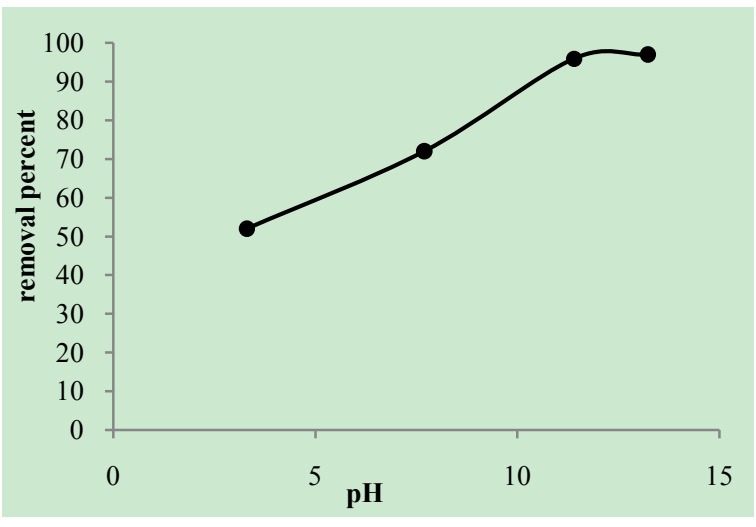

Figure 5. Effect of $\mathrm{pH},[\mathrm{MB}]=10 \mathrm{ppm}, 1 \mathrm{hr}$ reaction

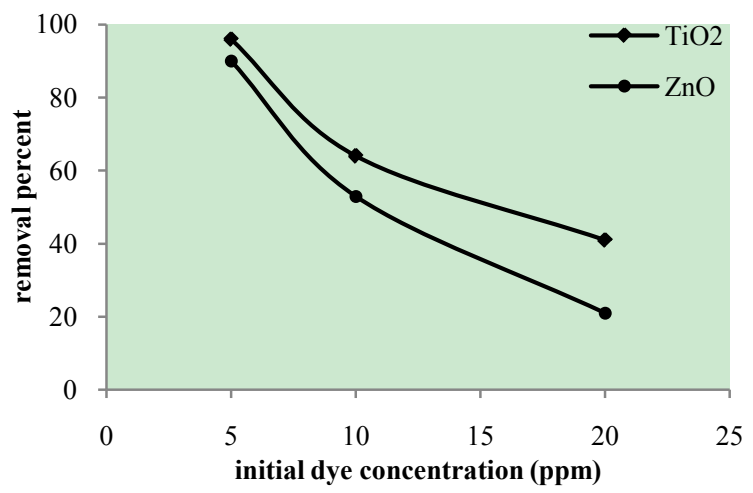

Figure 6. Comparison of $\mathrm{TiO}_{2}$ and $\mathrm{ZnO}$ sonophotoreactivity

\subsection{Comparison of the Sonophotocatalytic Removal Using $\mathrm{Tio}_{2}$ and Zno Nanopowders}

The photocatalytic reactivity results of $\mathrm{TiO}_{2}$ and $\mathrm{ZnO}$ nanopoders in methylene blue removal are presented in figure 6. Particle size of both photocatalysts is almost the same. $\mathrm{TiO}_{2}$ nanopowders show higher efficiency and higher percentage of dye removal than $\mathrm{ZnO}$ nanoparticles in all initial concentrations of methylene blue. As the initial concentration of dye increases, the differences in removal percent increase.

The photocatalytic activity of semiconductors is dependent on the band gap energy, crystallinity, particle size, surface area, pore structure and concentration of the impurities in the catalysts[26,27]. $\mathrm{ZnO}$ has higher band gap energy and this causes lower sonophotoreactivity than $\mathrm{TiO}_{2}$. In addition, this may be due to lower surface area and higher density of $\mathrm{ZnO}$ than $\mathrm{TiO}_{2}$.

\subsection{Removal Kinetics}

\subsubsection{Investigation of the Order of Rection in Photo and} Sonophotocatalytic Reaction

To estimate the kinetic rate of the removal reaction, an equation form of power law is used:

$$
-\mathrm{r}_{\text {dye }}=\mathrm{kC}_{\mathrm{cat}}{ }^{\mathrm{m}} \mathrm{C}_{\mathrm{A}}{ }^{\mathrm{n}}
$$

Where $\mathrm{k}$ is removal rate constant, $\mathrm{C}_{\mathrm{A}}$ is dye concentration, $\mathrm{n}$ is reaction order respect to the dye concentration, $\mathrm{C}_{\mathrm{cat}}$ is photocatalyst concentration and $\mathrm{m}$ is reaction order respect to the photocatalyst concentration. As the catalyst concentration is constant, the rate equation can be stated with observed rate constant $\left(\mathrm{k}_{\mathrm{obs}}\right)$ as follows:

$$
\begin{gathered}
-r_{\text {dye }}=-\mathrm{dC}_{\text {dye }} / \mathrm{dt}=\mathrm{k}_{\text {obs }} \cdot \mathrm{C}_{\mathrm{dye}}^{\mathrm{n}} \\
\mathrm{k}_{\mathrm{obs}}=\mathrm{k} \cdot \mathrm{C}_{\mathrm{cat}}^{\mathrm{m}}
\end{gathered}
$$

The pseudo-first order kinetic model $(\mathrm{n}=1)$ provide equation 3 to following form:

$$
-\ln \mathrm{C}_{\text {dye }} / \mathrm{C}_{\text {dye } 0}=\mathrm{k}_{\text {obs }} \mathrm{t}
$$

Figures 7 and 8 show plot of $-\operatorname{lnC}_{\text {dye }} / C_{\text {dye0 }}$ of $\mathrm{MB}$ versus irradiation time for photocatalytic and sonophotocatalytic reactions respectively. As it is clear from these figures, removal of the dye concentration obeys a linear pattern in this coordinate with good precision in the both cases. This means that the pseudo-first order kinetic of dye removal kinetic is acceptable for both photocatalytic and sonophotocatalytic processes, but comparison of the lines slop show that $\mathrm{k}_{\text {sonophotocatalysis }}>\mathrm{k}_{\text {photocatalysis }}$ and this shows that the sonophotocatalytic reaction is faster than photocatalytic at the same conditions.

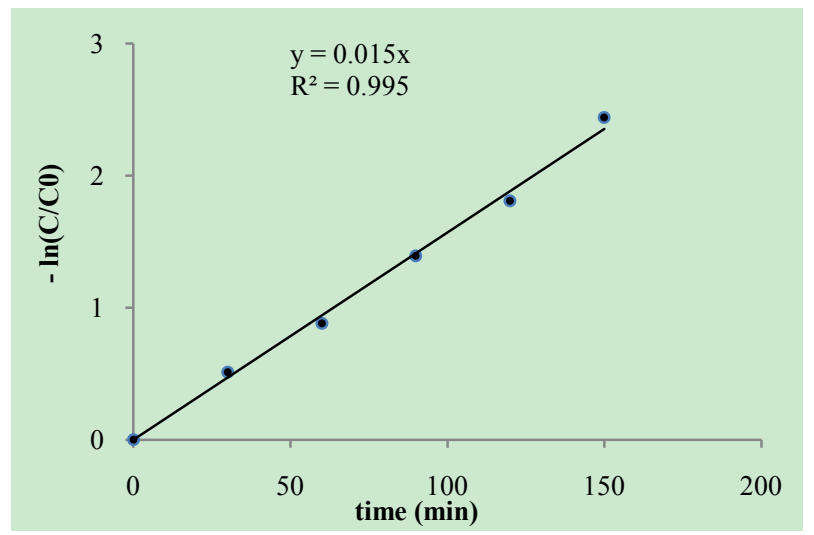

Figure 7. Pseudo-first order of the reaction rate in photocatalytic state, $\mathrm{C}_{\text {dye } 0}=10 \mathrm{ppm}$, room temperature 


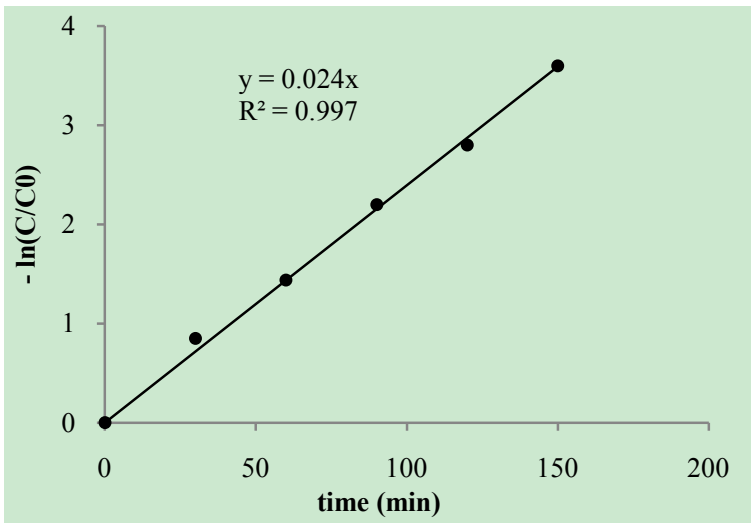

Figure 8. Pseudo first order of the reaction rate in sonophotocatalytic state, $C_{\text {dye }, 0}=10 \mathrm{ppm}$, room temperature

\subsubsection{Calculation of rate constant and order of reaction respect to photocatalyst concentration in sonophotocatalytic reaction.}

Logarithmic form of the equation 4 can be used to find out the order of reaction respect to catalyst dosage:

$$
\ln \mathrm{k}_{\mathrm{obs}}=\ln \mathrm{k}+\mathrm{m} \ln \mathrm{C}_{\mathrm{cat}}
$$

Three $\mathrm{k}_{\mathrm{obs}}$ are determined in three different catalyst dosages $(0.1,0.15,0.2 \mathrm{~g} / \mathrm{l})$ base on determination route of section 3.6.1 and the curves are plotted in figure 9. The regression results are listed in table 1 . The catalyst concentrations were selected lower than its optimum dosage. These results are then used for determination order of reaction rate respect to the concentration of catalyst (parameter $\mathrm{m}$ in equation 2 ).

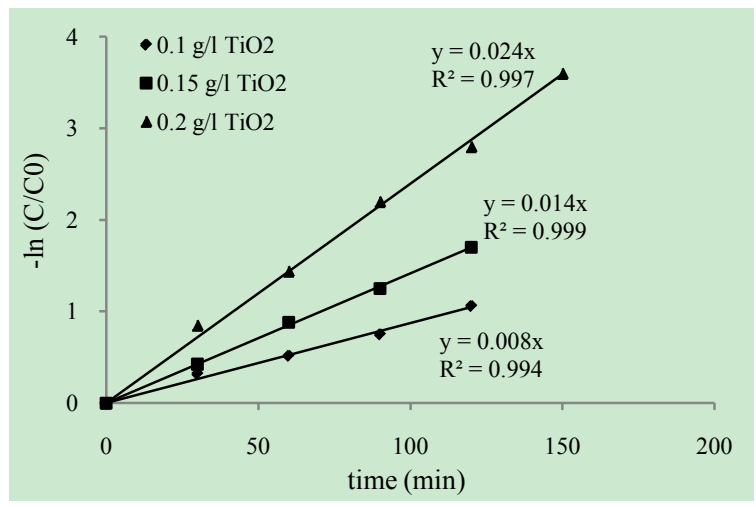

Figure 9. Determination of $\mathrm{K}_{\mathrm{obs}}$ in three dosages of photocatalyst

Table 1. $\mathrm{k}_{\mathrm{obs}}$ values in different concentrations of photocatalyst

\begin{tabular}{|c|c|c|}
\hline $\mathrm{TiO}_{2}$ dosage $(\mathrm{g} / \mathrm{l})$ & $\mathrm{k}_{\text {obs }}(1 / \mathrm{min})$ & $\mathrm{R}^{2}$ \\
\hline 0.1 & 0.0087 & 0.993 \\
\hline 0.15 & 0.0142 & 0.999 \\
\hline 0.2 & 0.0240 & 0.997 \\
\hline
\end{tabular}

At this step considerations of the order of reaction respect to the concentration of catalyst can be done. Plotting $\ln \left(\mathrm{k}_{\mathrm{obs}}\right)$ versus $\ln \left(\mathrm{C}_{\mathrm{cat}}\right)$ base on equation 6 is presented in figure 10 and gives $\mathrm{m}$ and $\mathrm{k}$ (equation 2), according to calculating slope and intercept of the line.

Slope of the line is 1.45 which is the order of reaction rate respect to the concentration of photocatalyst and its intercept is -1.437 . Therefore the reaction rate constant $(\mathrm{k})$ is 0.237 $(\mathrm{gr} / \mathrm{l})^{-1.45} / \mathrm{min}$ for sonophotocatalytic reaction at room tem- perature. So the rate equation for sonophotocatalytic process at room temperature can be stated as follows:

$$
-\mathrm{r}_{\mathrm{A}}=-\mathrm{dC}_{\mathrm{A}} / \mathrm{dt}=0.237 \cdot \mathrm{C}_{\mathrm{A}} \cdot \mathrm{C}_{\mathrm{cat}}{ }^{1.45}
$$

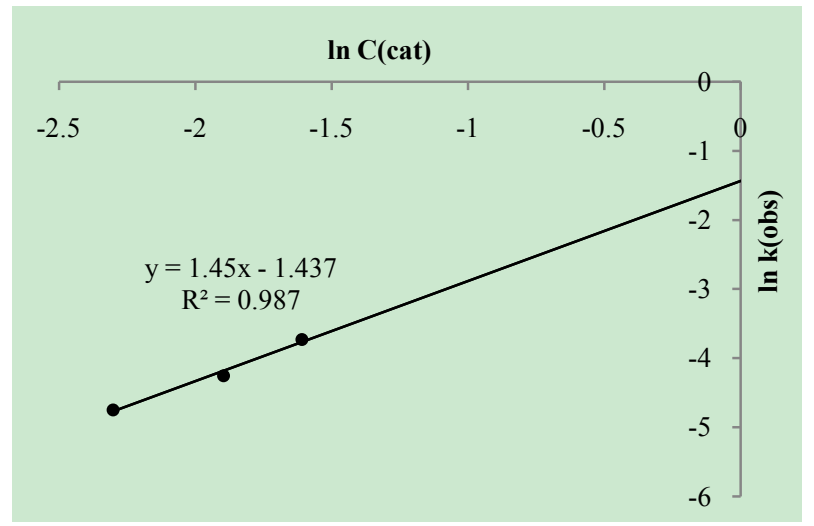

Figure 10. Determinations of $\mathrm{m}$ and $\mathrm{k}$ in sonophotocatalytic reaction

where dye concentration $\left(\mathrm{C}_{\mathrm{A}}\right)$ in this equation is based on $(\mathrm{ppm})$ and concentration of catalyst $\left(\mathrm{C}_{\mathrm{cat}}\right)$ is based on $(\mathrm{g} / \mathrm{l})$. The value of $k$ in the rate equation depends on temperature and Arrhenius equation shows this dependence as follows:

$$
\mathrm{k}=\mathrm{k}_{0} \mathrm{e}^{-\mathrm{E} / \mathrm{RT}}
$$

$\mathrm{k}_{0}$ is pre-exponential factor and $\mathrm{E}(\mathrm{j} / \mathrm{mol})$ is activation energy of the reaction. The sonophotocatalytic process of dye removal was conducted at three temperatures and the experimental results were analyzed to determine the reaction rate constant at each temperature. Table 2 specifies $\mathrm{k}_{\text {obs }}$ and $\mathrm{k}$ at three temperatures and catalyst dosage of $0.2 \mathrm{~g} / \mathrm{l}$. The Arrhenius plot of these data is presented in figure 11 .

Table 2. $\mathrm{k}_{\mathrm{obs}}$ and $\mathrm{k}$ value in sonophotocatalytic process at different temperatures, $\mathrm{C}_{\mathrm{cat}}=0.2 \mathrm{~g} / \mathrm{l}$

\begin{tabular}{|c|c|c|}
\hline $\mathrm{T}\left({ }^{\circ} \mathrm{C}\right)$ & $\mathrm{k}_{\text {obs }}(1 / \mathrm{min})$ & $\mathrm{k}(\mathrm{gr} / 1)^{-1.45} / \mathrm{min}$ \\
\hline 22 & 0.0158 & 0.1624 \\
\hline 47 & 0.0240 & 0.2467 \\
\hline 67 & 0.0288 & 0.2960 \\
\hline
\end{tabular}

$\mathbf{1} / \mathbf{T}$ $\begin{array}{lllllll}0.0029 & 0.003 & 0.0031 & 0.0032 & 0.0033 & 0.0034 & 0.0035\end{array}$

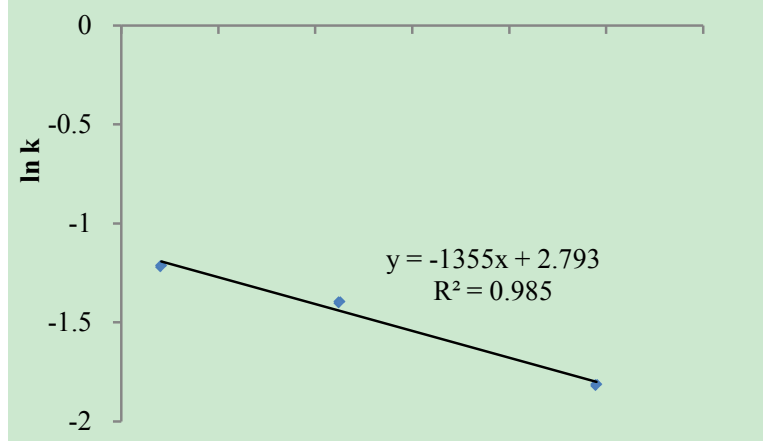

Figure 11. Arrhenius plot of the rate constant in sonophotocatalytic reaction

Regression of the experimental data in figure 11 gives activation energy and pre-exponential factor of the reaction (equation 8) using slope and intercept of the line. Therefore the calculated rate constants are $E=-11265 \mathrm{j} / \mathrm{mol}$ and $\mathrm{k}_{0}=$ $0.272(\mathrm{~g} / \mathrm{l})^{-1.45} / \mathrm{min}$. 


$$
-\mathrm{r}_{\mathrm{A}}=-\mathrm{dC}_{\mathrm{A}} / \mathrm{dt}=0.272 \mathrm{e}^{-11265 / \mathrm{RT}} \mathrm{C}_{\mathrm{A}} \mathrm{C}_{\text {cat }}{ }^{1.45}
$$

This equation describe degradation rate of $\mathrm{MB}$ in the sonophotocatalysis process with dimension $\mathrm{g} / \mathrm{l}$.min.

\section{Conclusions}

In this study the dye MB was appropriately mineralized by separate and simultaneous photocatalytic and sonocatalytic reactions in the presence of nanoparticles titanium dioxide in the form of slurry. The effect of efficiency parameters like dosage of catalyst, concentration of dye, UV power $\mathrm{pH}$ and type of nanocatalyst were investigated. It was found that optimum dosage of catalyst was $1,0.2$ and 0.2 for sonocatalytic, photocatalytic and sonophotocatalytic reactions respectively. The results revealed that the dye removal was inversely proportional to the initial methylene blue concentration in all processes. photocatalysis seems to be more efficient than sonocatalysis in the same environmental situations. the removal rate of dye increases with increasing UV power from 6 to $24 \mathrm{~W}$. photocatalytic and sonophotocatalytic removal of methylene blue obey pseudo first order kinetic at low initial concentrations and the sonophotocatalytic kinetic parameters was determined for initial $\mathrm{MB}$ concentration of $10 \mathrm{ppm}$. Also it was observed that $\mathrm{TiO}_{2}$ was found to be more efficient than $\mathrm{ZnO}$ for methylene blue removing via photocatalytic process.

\section{REFERENCES}

[1] M. Saquib, M. Abu Tariq, M.M. Haque, M. Muneer, Photocatalytic degradation of disperses blue using $\mathrm{UV} / \mathrm{TiO} 2 / \mathrm{H} 2 \mathrm{O} 2$ process, J. Environmental Management. 88, 300-306, (2008)

[2] R. Jain, M. Shrivastava, Photocatalytic removal of hazardous dye cyanosine from industrial waste using titanium dioxide, J. Hazardous Materials. 152, 216-220, (2008)

[3] A.H. Mahvi, M. Ghanbarian, S. Nasseri, A. Khairi, Mineralization and discoloration of textile wastewater by $\mathrm{TiO} 2$ nanoparticles, J. Desalination. 239, 309-316, (2009)

[4] E.A. El-Sharkawy, A.Y. Soliman, K.M. Al-Amer, Comparative study for the removal of methylene blue via adsorption and photocatalytic degradation, J. Colloid and Interface Science. 310, 498-508, (2007)

[5] A.R. Lang (ED.), Dyes and pigments: new research, Nova Science, New York , 44-45, (2009)

[6] Zh. Shan, W. Wang, X. Lin, H. Ding, F. Huang, Photocatalytic degradation of organic dyes on visible-light responsive photocatalyst $\mathrm{PbBiO}_{2} \mathrm{Br}$, J. Solid State Chemistry. 181, 1361-136, (2008)

[7] M.H. Entezari, Z. Sharif Al-Hoseini, Sono-sorption as a new method for the removal of methylene blue from aqueous solution, J. Ultrasonics Sonochemistry. 14, 599-604, (2007)

[8] H. Lachheb, E. Puzenat, A. Houa, M. Ksibi, E. Elaloui, Ch. Guillard, J.M. Herrmann, Photocatalytic degradation of various types of dyes (Alizarin S, Crocein Orange G, Methyl Red, Congo Red, Methylene Blue) in water by UV-irradiated titania, J. Applied Catalysis B: Environmental. 39, 75-90, (2002)

[9] M.R. Sohrabi, M. Ghavami, Photocatalytic degradation of Direct Red 23 dye using UV/TiO2: Effect of operational parameters, J. Hazardous Materials. 153, 1235-1239, (2008)

[10] J. Chen, M. Liu, L. Zhang, J. Zhang, L. Jin, Application of nano $\mathrm{TiO} 2$ towards polluted water treatment combined with electro-photochemical method, J.Water Research. 37, 3815-3820, (2003)

[11] A.1. Kokorin, D.W.Ba hnemann (Eds.), Chemical Physics of Nanostructured Semiconductors, Utrecht, Boston, 1-31, (2003)

[12] p. Boule, D.W. Bahnemann, P.K.J.Robertson (Eds.), Handbook of environmental photochemistry, Vol. 2, Part M, Springer-Verlag Berlin Heidelberg, 1-47, (2005)

[13] J. Moon, Ch.Y. Yun, K.W. Chung, M. Kang, J. Yi, Photocatalytic activation of $\mathrm{TiO} 2$ under visible light using Acid Red 44, J. Catalysis Today. 87, 77-86, (2003)

[14] A.S. González, S.S. Martínez, Study of the sonophotocatalytic degradation of basic blue 9 industrial textile dye over slurry titanium dioxide and influencing factors, J. Ultrasonics Sonochemistry. 15, 1038-1042, (2008)

[15] D.E. Kritikos, N.P. Xekoukoulotakis, E. Psillakis, D. Mantzavinos, Photocatalytic degradation of reactive black 5 in aqueous solutions: Effect of operating conditions and coupling with ultrasound irradiation, J. water research. 41, $2236-2246,(2007)$

[16] Ch.H. Wu, H.W. Chang, J. Chern, Basic dye decomposition kinetics in a photocatalytic slurry reactor, J. Hazardous Materials. B137, 336-343, (2006)

[17] [17] R. Cella, H. A. Stefani, Ultrasound in heterocycles chemistry, J. Tetrahedron. 65, 2619-2641, (2009)

[18] N.S. Allen, M. Edge, A. Ortega, Ch.M. Liauw,J. Stratton, R.B. McIntyre, Factors affecting the interfacial adsorption of stabilizers on to titanium dioxide particles (flow microcalorimetry, modelling, oxidation and FTIR studies): Nano versus pigmentary grades, J. Dyes and Pigments. 70, 192-203, (2006)

[19] C.G. Joseph, G.L. Puma, A. Bono, D. Krishnaiah, Sonophotocatalysis in advanced oxidation process: A short review, J. Ultrasonics Sonochemistry. 16, 583-589, (2009)

[20] F. banat, S. Al-Asheh, M. Al-Rawashteh, M. Nusair, photodegradation of methylene blue dye bye the $\mathrm{UV} / \mathrm{H}_{2} \mathrm{O}_{2}$ and UV/aceton oxidation processes, J. Desalination. 18, 225-232, (2005)

[21] N. Shimizu, C. Ogino, M.F. Dadjour, T. Murata, Sonocatalytic degradation of methylene blue with $\mathrm{TiO} 2$ pellets in water, J. Ultrasonics Sonochemistry. 14, 184-190, (2007)

[22] M. Mrowetz, C. Pirola, E. Selli, Degradation of organic water pollutants through sonophotocatalysis in the presence of TiO2, J. Ultrasonics Sonochemistry. 10, 247-254, (2003)

[23] M. Muruganandham1, M. Swaminathan, TiO2-UV photocatalytic oxidation of Reactive Yellow 14: Effect of operational parameters, J. Hazardous Materials. B135, 78-86, 
(2006)

[24] M.A. Behnajady, N. Modirshahla, N. Daneshvar, M. Rabbani, Photocatalytic degradation of an azo dye in a tubular continuous-flow photoreactor with immobilized $\mathrm{TiO} 2$ on glass plates, J. Chemical Engineering. 127, 167-176, (2007)

[25] N. Daneshvar, D. Salari, A.R. Khataee, Photocatalytic degradation of azo dye acid red 14 in water: investigation of the effect of operational parameters, J. Photochemistry and Photobiology A: Chemistry. 157, 111-116, (2003)
[26] R.J. Tayadea, P.K. Suroliaa, R.G. Kulkarnib, R.V. Jasra, Photocatalytic degradation of dyes and organic contaminants in water using nanocrystalline anatase and rutile $\mathrm{TiO} 2, \mathrm{~J}$. Science and Technology of Advanced Materials. 8, 455-46, (2007)

[27] H. de Lasa, B. Serrano, M. Salaices, Photocatalytic Reaction Engineering, Springer Science, United States of America, 1-12, (2005) 